\title{
Humidity sensing characteristics of hydrotungstite thin films
}

\author{
G V KUNTE, S A SHIVASHANKAR and A M UMARJI* \\ Materials Research Centre, Indian Institute of Science, Bangalore 560 012, India
}

MS received 28 July 2007

\begin{abstract}
Thin films of the hydrated phase of tungsten oxide, hydrotungstite $\left(\mathrm{H}_{2} \mathrm{WO}_{4} \cdot \mathrm{H}_{2} \mathrm{O}\right)$, have been grown on glass substrates using a dip-coating technique. The $b$-axis oriented films have been characterized by $\mathrm{X}$-ray diffraction and scanning electron microscopy. The electrical conductivity of the films is observed to vary with humidity and selectively show high sensitivity to moisture at room temperature. In order to understand the mechanism of sensing, the films were examined by X-ray diffraction at elevated temperatures and in controlled atmospheres. Based on these observations and on conductivity measurements, a novel sensing mechanism based on protonic conduction within the surface layers adsorbed onto the hydrotungstite film is proposed.
\end{abstract}

Keywords. Tungsten oxide; hydrotungstite; humidity sensor; selectivity; protonic conduction.

\section{Introduction}

The use of activated tungsten oxide as a gas sensor was first reported in 1967 (Shaver 1967). Since then, and especially in recent years, there has been an interest in the study of tungsten oxides for gas sensing applications. Tungsten oxide appears to be a promising material for sensors that detect and measure various gases. Tungsten oxide-based materials have been used for the sensing of various gases, especially $\mathrm{H}_{2} \mathrm{~S}$ (Barrett et al 1990), $\mathrm{NO}_{x}$ (Nelli et al 1996) and ozone (Qu and Wlodarski 2000). A variety of tungstate materials, such as thick-film manganese tungstate, have been applied as humidity sensors (Qu and Mayer 1997). The humidity sensing characteristics of bulk metal oxide-tungsten oxide systems have also been studied in the literature (Ichinose 1993).

Thin films of tungsten oxide have been prepared by various physical and chemical methods, often leading to different properties (Granqvist 1995). Tungsten oxide films for $\mathrm{NO}_{x}$ sensing have been produced by thermal evaporation of tungsten oxide powder (Cantalini et al 1996). Tungsten oxide films have also been grown by d.c. and r.f. sputtering and have been studied for their electrochromic and gas sensing properties (Smith et al 1993). Electrochemical and chemical techniques are convenient and have been widely employed for the preparation of tungsten oxide films. Tungsten oxide films for electrochromic applications have been grown by chemical vapour deposition using hexacarbonyl tungsten as precursor (Maruyama and Arai 1994) and with tungsten ethoxide as precursor (Riaz 1993). Other techniques such as plasma-

*Author for correspondence (umarji@mrc.iisc.ernet.in) enhanced chemical vapour deposition have also been used. Tungsten oxide films have also been prepared by sol-gel techniques, using different precursors such as tungsten oxychloride (Pyper et al 1998) and tungstic acid (Bedja et al 1994).

We have reported earlier the growth and characterization of dip-coated hydrotungstite films for humidity sensing (Kunte et al 2005). Thin films of the tungsten oxidebased material, hydrotungstite, were prepared on glass substrates by the dip-coating technique, using a solution of ammonium tungstate as the precursor. The resistance of these films was found to be dependent on the humidity of the ambient, suggesting their suitability as humidity sensors. Here, an effort has been made to understand the mechanism of sensing. Based on the quantitative humidity sensing measurements and in situ X-ray diffraction data, a novel mechanism for sensing is proposed.

\section{Experimental}

Thin films of a hydrated form of tungsten oxide viz. hydrotungstite $\left(\mathrm{H}_{2} \mathrm{WO}_{4} \cdot \mathrm{H}_{2} \mathrm{O}\right)$, were grown on glass substrates using a dip-coating technique. The precursor used for dip-coating was ammonium tungstate $\left[\left(\mathrm{NH}_{4}\right)_{2} \mathrm{WO}_{4}\right.$. $x \mathrm{H}_{2} \mathrm{O}$. The films were grown on the substrate by repeated dipping of the substrate into the precursor solution $(0.05 \mathrm{M}$ solution of ammonium tungstate in water) and drying at $100^{\circ} \mathrm{C}$ over a hot plate. This dipping and drying process was repeated 15-20 times to achieve the required thickness. The films were finally calcined at $500^{\circ} \mathrm{C}$ for $4 \mathrm{~h}$. The films were characterized by XRD and scanning electron microscopy (SEM). The details of the film deposition and characterization have been reported elsewhere (Kunte et al 2005). 
The electrical resistance of the films was observed to be sensitive to the humidity content of the ambient and, hence, it was decided to investigate the humidity-sensing characteristics of these films. The sensing measurements were carried out in a homemade gas-sensing measurement system, wherein the resistance of the film could be measured with control over the temperature and the ambient. Controlled (desired) mixtures of gases could be injected into the system using a system of valves and electronic mass-flow controllers. In particular, for humidity sensing measurements, specific (percentage) relative humidities were achieved by saturating dry nitrogen with water and subsequently diluting it with dry air.

The resistance of the hydrotungstite films was measured using a Keithley 2700 multimeter. For the measurement, an interdigitated electrode pattern was used. Gold electrodes were sputtered on to the films through a mask, and electrical contacts made with silver paint. The electrode pattern is shown as the inset in figure 1. This pattern gives an effective sensor area of $10.88 \mathrm{~mm}^{2}$.

The ohmic nature of the gold contacts was verified by doing the $I-V$ measurements in the voltage range -10 to +10 volts. A typical $I-V$ curve is shown in figure 1 and is linear and symmetric in the voltage range of measurement.

Possible changes in the crystal structure of the hydrotungstite films under humidity sensing conditions were monitored by conducting X-ray diffraction measurements with the film placed in the closed chamber of the high temperature attachment (Bruker) to a Scintag (Model XRG 3000) X-ray diffractometer. Diffraction patterns were recorded under different ambients at temperatures up to $160^{\circ} \mathrm{C}$.

\section{Results and discussion}

\subsection{Structural characterization of films}

The as-deposited films were characterized by X-ray diffraction, which reveals that they are composed of the hy-

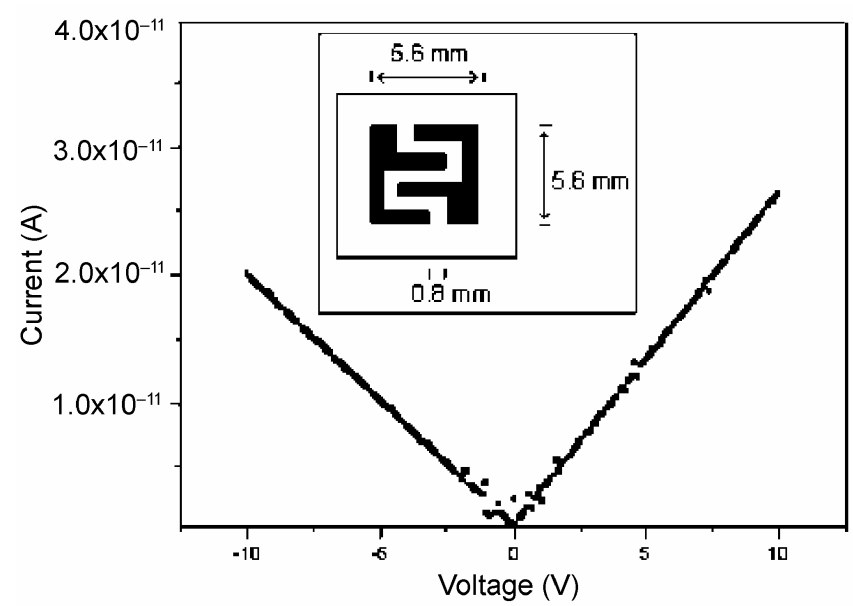

Figure 1. $I-V$ characteristics of film in the range -10 to $+10 \mathrm{~V}$. Inset shows the electrode pattern used. Darkened region shows sputtered gold electrode. drotungstite phase $\left(\mathrm{H}_{2} \mathrm{WO}_{4} \cdot \mathrm{H}_{2} \mathrm{O}\right)$ (JCPDS No. 18-1420). The films were observed to have a strong $b$-axis orientation, with only the (010), (020) and (030) peaks being seen in the XRD pattern. A typical XRD pattern of an asdeposited hydrotungstite film is shown in figure 2 .

Scanning electron microscopy showed the surfaces of the films to be rough, with a large number of particulates on the surface. The average size of the particulates was estimated to be $0 \cdot 1 \mu \mathrm{m}$. An electron microscope image is shown in figure 3. It may be seen from the micrograph that, though the film is covered by a large number of particulates, the underlying film is not very rough. Crosssectional scanning electron microscopy showed the thickness of the films to be in the range $1-5 \mu \mathrm{m}$.

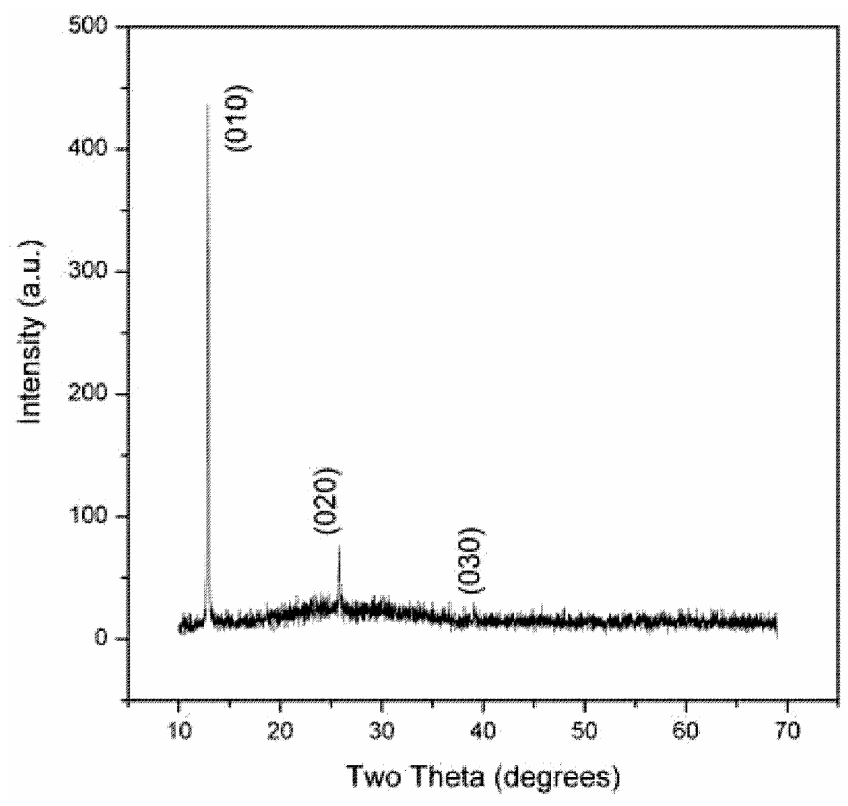

Figure 2. XRD pattern of film of $b$-axis oriented $\mathrm{H}_{2} \mathrm{WO}_{4} \cdot \mathrm{H}_{2} \mathrm{O}$.

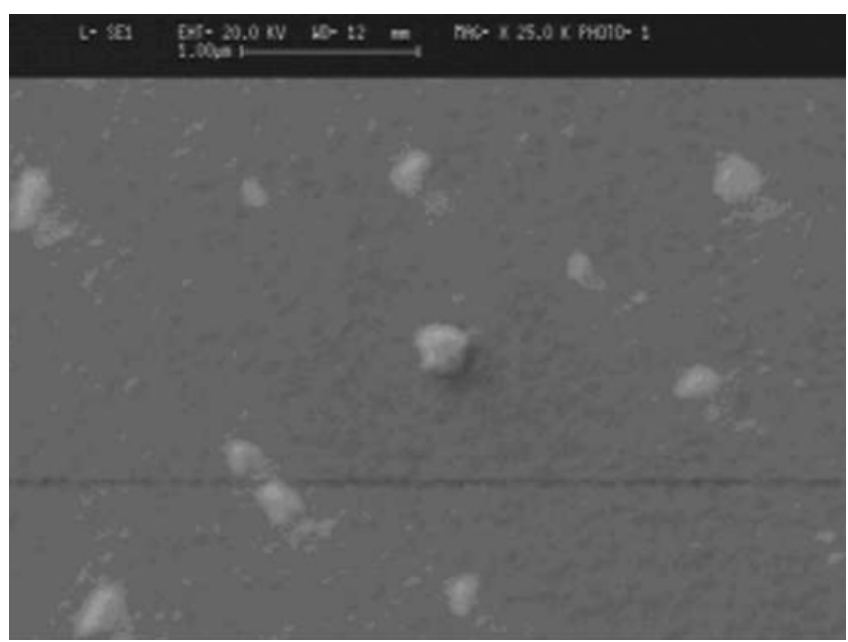

Figure 3. SEM image of hydrotungstite film showing particulates on smooth underlayer. 


\subsection{Humidity sensing}

The electrical resistance of the films was measured as a function of humidity. During the course of each experiment, the resistance of the film was measured continuously, while switching the ambient back and forth between dry air and air with a known value of relative humidity. Figure 4 shows the typical sensitivity of the sensor to humid air at two different temperatures, $20^{\circ} \mathrm{C}$ and $30^{\circ}$. Figure 4 also shows the real-time change in resistance with the application of a pulse of $27 \%$ humidity. The dip in resistance seen in the plot is due to switching from dry air to humid air for a certain span of time and switching back to dry air. Effectively, pulses of humid air of different percentage humidity were supplied to the sensor. It is observed that the film resistance decreases
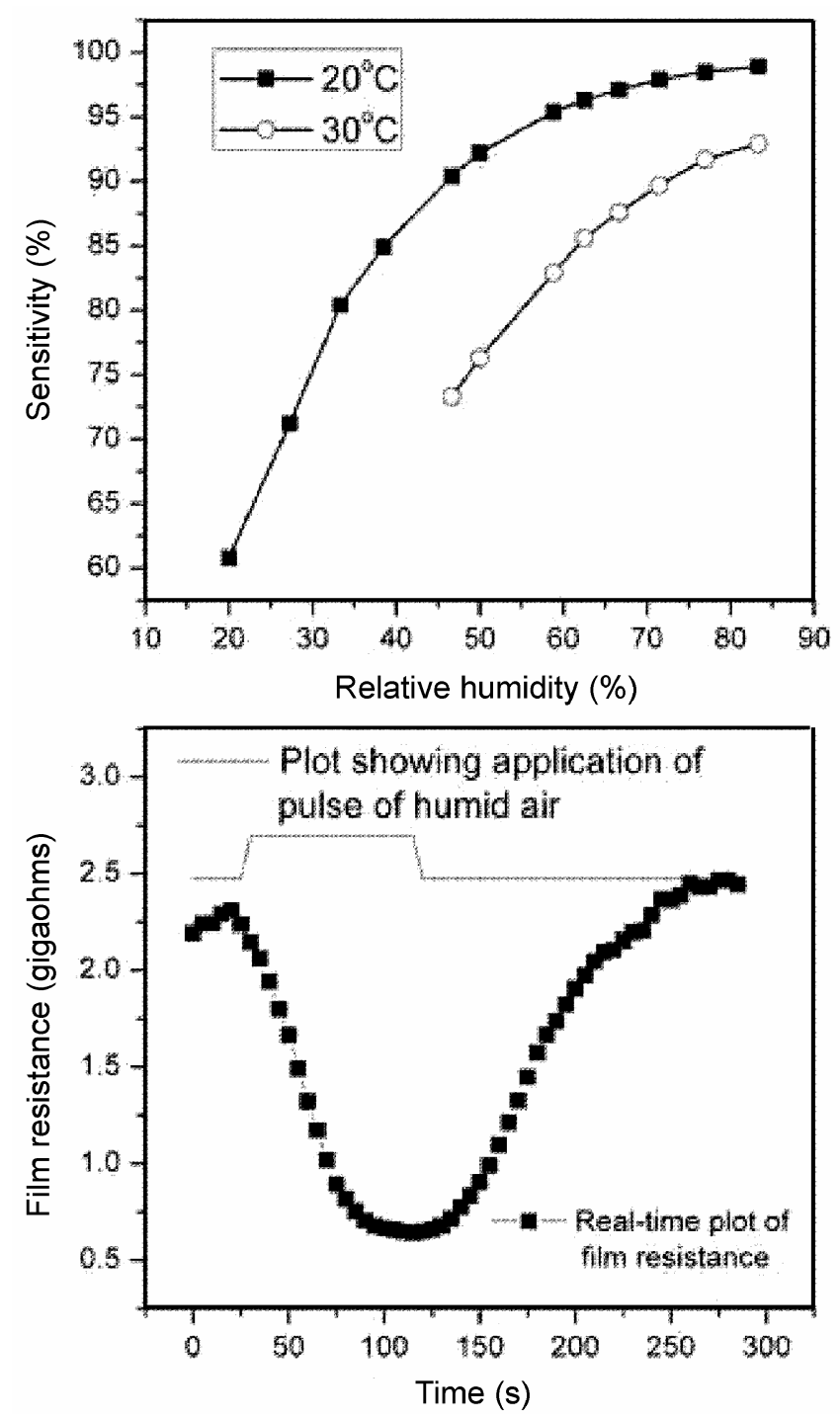

Figure 4. Sensitivity of films at $20^{\circ} \mathrm{C}$ and $30^{\circ} \mathrm{C}$. Also shown is a real-time plot showing variation in sensor resistance on exposure to $27 \%$ relative humidity at $20^{\circ} \mathrm{C}$. exponentially with increase in the relative humidity. To quantify the sensor response, the sensitivity to humidity $S$, is defined as

$$
S=\left(R_{\text {dry air }}-R_{\text {humid air }}\right) / R_{\text {dry air }},
$$

expressed as a percentage.

From the sensing measurements, the response and recovery times of the sensor were computed. The response time is defined as the time required for the sensor to reach minimum resistance after the ambient is switched from dry air to humid air. The response time was found to be of the order of $45 \mathrm{~s}$. Similarly, the recovery time is defined as the time required for the sensor to reach its base resistance (resistance in dry air), after switching the ambient is switched back from humid to dry air. The recovery time was found to be of the order of $100 \mathrm{~s}$.

At higher temperatures, it was observed that the sensitivity of the film to humidity decreased. Indeed, no sensitivity to humidity could be observed when the temperature of the hydrotungstite film was held above $50^{\circ} \mathrm{C}$. Figure 4 also shows the comparison of the resistance vs relative humidity behaviour measured at $20^{\circ} \mathrm{C}$ and $30^{\circ} \mathrm{C}$. The exponential variation of the sensitivity with humidity was observed both at $30^{\circ} \mathrm{C}$ and $20^{\circ} \mathrm{C}$, but the sensitivity is much lower at $30^{\circ} \mathrm{C}$. Specifically, the sensor responds to relative humidity in the range $15-100 \%$ at $20^{\circ} \mathrm{C}$ whereas, at $30^{\circ} \mathrm{C}$, the response is limited to a relative humidity range of only $40-100 \%$.

For any gas sensor, selectivity is the ability to distinguish between different chemical species present in the ambient being tested. The higher the selectivity, the better is the sensor in detecting the species of interest. For the hydrotungstite films, the sensitivity was tested for ethanol, acetone, hexane and toluene. The concentration used during the test was equivalent to the concentration of moisture in air containing $100 \%$ relative humidity. These chemicals are often present in industrial and domestic environments. It was observed that, within the operating range of the sensor, the sensitivity of the hydrotungstite film to ethanol and acetone was very low, i.e. only about $5 \%$ at high concentrations; the sensitivity to hexane and toluene was zero to within the sensitivity of the measurement. This result is very encouraging, as the crosssensitivity of this sensor to common contaminants is low. Table 1 summarizes the cross-sensitivity data.

\subsection{Mechanism of sensing}

3.3a In situ X-ray diffraction studies: As part of an effort to understand the mechanism of sensing, powder X-ray diffraction of the hydrotungstite film in a controlled atmosphere and at elevated high temperatures was carried out. To begin with, XRD patterns of the films were recorded in a dry atmosphere (ultra-high purity nitrogen) and in a humid atmosphere (obtained by bubbling dry nitrogen through water). No difference was observed 
in the XRD patterns observed under these two ambients (figure 5). Specifically, the position and intensity of the (010) peak at $2 \theta=12.9$ remained unaffected by the presence or absence of humidity. This implies that the water moiety in the lattice of the hydrated phase of the hydrotungstite is not directly responsible for sensing humidity.

The next series of XRD measurements was carried out in a humid atmosphere at different temperatures. At $60^{\circ} \mathrm{C}$, where no sensitivity to humidity had been observed, the various peak positions and relative intensities remain the same as at room temperature $\left(28^{\circ} \mathrm{C}\right)$. That is, the absence of sensitivity to moisture at $60^{\circ} \mathrm{C}$ is not caused by any change in crystal structure of the hydrotungstite film. However, in the diffraction pattern taken with the film at $160^{\circ} \mathrm{C}$, the prominent peak at $12.9^{\circ}$ was entirely lost. At this temperature, the material was dehydrated, leading to the collapse of the crystalline structure. Figure 5 shows the X-ray diffraction patterns of the film at different temperatures to which the sample was heated, along with the comparison of XRD patterns obtained under different humidity conditions.

An attempt was made to see whether the crystalline hydrated phase was restored upon cooling. In particular, the hydrotungstite film was allowed to cool at the rate of $1^{\circ} \mathrm{C} / \mathrm{min}$ from $160^{\circ} \mathrm{C}$ to room temperature in a humid atmosphere. Sensing measurements showed that, after the material was once dehydrated, the (hydrated) phase was

Table 1. Cross-sensitivity data for the films for other vapours.

\begin{tabular}{lcc}
\hline & Sensitivity at $20^{\circ} \mathrm{C}$ & Sensitivity at $30^{\circ} \mathrm{C}$ \\
\hline Ethanol & $<5 \%$ & $<5 \%$ \\
Acetone & $<5 \%$ & $<5 \%$ \\
Hexane & Nil & Nil \\
Toluene & Nil & Nil \\
\hline
\end{tabular}

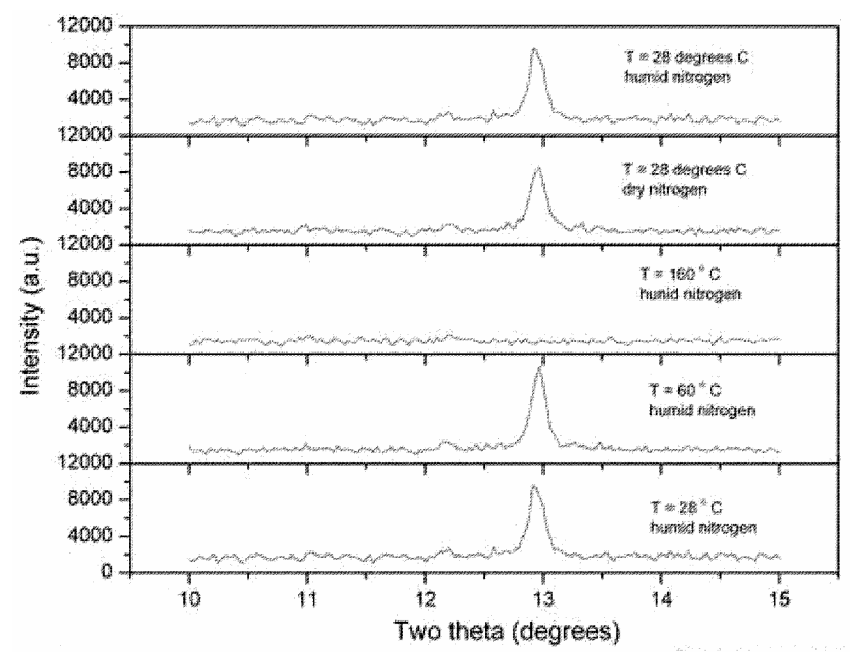

Figure 5. Comparison of XRD patterns of films in dry and humid atmosphere and at $20^{\circ} \mathrm{C}, 30^{\circ} \mathrm{C}$ and $160^{\circ} \mathrm{C}$ during heating. not restored and the sensitivity of the film to humidity was lost. Furthermore, it was found that, even after exposure to humidity for a day, the hydrotungstite film heated to $160^{\circ} \mathrm{C}$ did not recover its former crystalline phase.

3.3b Mechanism of sensing: Some sensing mechanisms are well known for semiconducting oxide gas sensors. The most commonly observed is a mechanism based on defects in the sensing material, wherein the crystal defects interact with the molecules of the sensed gas on the surface, thus causing a change in the number of charge carriers in the material (Williams 1999). This is observed as a change in the resistance of the sensor. Another mechanism is the physical or chemical adsorption of the gas molecules on the surface, leading either to a change in the carrier concentration, and hence the resistance by the exchange of electrons (acceptance or donation) between the adsorbed species and the material (Rothschild et al 2002), or to a change in the resistance due to a surface conduction mechanism involving the adsorbed molecules (Kulwicki 1991).

The data obtained from the humidity sensing measurements and the high-temperature X-ray diffraction experiments reported here give an indication of the mechanism through which hydrotungstite films sense humidity. At room temperature, any mechanism based on defects may be ruled out. Further, high-temperature X-ray diffraction shows that the water in the lattice of the hydrotungstite is not directly affected by the humidity in the ambient. Even so, the water of crystallization in the crystalline lattice may interact with water vapour in the ambient, thus causing the water molecules in the vapour to physisorb on the surface of the sensor, forming a surface layer. The physisorbed water dissociates into $\mathrm{H}_{3} \mathrm{O}^{+}$and $\mathrm{OH}^{-}$, because of high electrostatic fields at the interface between the sensor and the adsorbed layer. Charge transport occurs by the movement of a proton from a $\mathrm{H}_{3} \mathrm{O}^{+}$ion to an adjacent water molecule, and so on. Thus, protonic conduction is set up on the surface. This mechanism of charge transport is known as the Grotthuss chain reaction (Agmon 1995) and is believed to represent the conduction mechanism in the surface layer of a humidity-sensitive film (Kulwicki 1991). This protonic conduction causes the observed drop in resistance in a humid atmosphere. At low humidity, only the surface protonic conduction causes the change in resistance. However, at higher values of humidity, water may condense on the film, and hence electrolytic conduction also occurs, causing a larger drop in resistance.

This explanation of the sensing mechanism in hydrotungstite is further supported by the fact that ethanol, which is chemically similar to water in some respects, and is also an electron donor (through the two lone pairs of electrons on the $\mathrm{O}$ atom), has a very low effect (almost none) on the resistance of the sensor. If electron donation to the sensing material were the reason for the sensitivity, ethanol with two lone pairs on the $\mathrm{O}$ atom, just as in water, 
should show a comparable sensitivity, which is not observed here. The mechanism proposed above explains the observed sensing behaviour quite well, although only qualitatively. What needs to be examined is whether the actual behaviour, i.e. the exponential dependence of the resistance with relative humidity, can be quantified by this mechanism.

\section{Conclusions}

Thin films of hydrotungstite $\left(\mathrm{H}_{2} \mathrm{WO}_{4} \cdot \mathrm{H}_{2} \mathrm{O}\right)$ were grown on glass by a dip-coating technique. The films were studied for their humidity-sensing ability. The films were seen to show high sensitivity and selectivity to humidity at room temperature. X-ray diffraction studies at high temperature and in controlled ambient were carried out and, based on these results, a mechanism for sensing involving surface protonic conduction within the physisorbed water layer has been proposed.

\section{References}

Agmon N 1995 Chem. Phys. Lett. 244456

Barrett E P S, Georgiades G E and Sermon P A 1990 Sensors Actuators B1 116
Bedja I, Hotchandani S, Carpenties R, Vinodgopal K and Kamat P V 1994 Thin Solid Films 347195

Cantalini C, Pelino M, Sun H T, Faccio M, Santucci S, Lozzi L and Passacantando M 1996 Sensors Actuators B35-36 112

Granqvist C G 1995 Handbook of inorganic electrochromic materials (Amsterdam: Elsevier)

Ichinose N 1993 Sensors Actuators B13-14 100

Kulwicki B M 1991 J. Am. Ceram. Soc. 74697

Kunte G V, Ail U, Shivashankar S A and Umarji A M 2005 Bull. Mater. Sci. 28243

Maruyama T and Arai S 1994 J. Electrochem. Soc. 141 1021

Nelli P, Depero L E, Ferroni M, Groppelli S, Guidi V, Ronconi F, Sangaletti L and Sberveglieri G 1996 Sensors Actuators B31 89

Pyper O, Schollborn R R, Donkers J J T M and Krings L H M 1998 Mater. Res. Bull. 331095

Qu W and Mayer J-U 1997 Sensors Actuators B40 175

Qu W and Wlodarski W 2000 Sensors Actuators B64 42

Riaz U 1993 Thin Solid Films 23515

Rothschild A, Komem Y and Ashkenasy N 2002 J. Appl. Phys. 927090

Shaver P J 1967 Appl. Phys. Lett. 11255

Smith D J, Vetelino J F, Falconer R S and Wittman E L 1993 Sensors Actuators B13 264

Williams D E 1999 Sensors Actuators B57 1 